\title{
Influence of endotracheal tube diameter on forced deflation flow-volume curves in rhesus monkeys
}

\author{
J. Hammer*, C.J.L. Newth**
}

Influence of endotracheal tube diameter on forced deflation flow-volume curves in rhesus monkeys. J. Hammer, C.J.L. Newth. (C) ERS Journals Ltd 1997.

ABSTRACT: The forced deflation (FD) technique is the recommended gold standard to generate forced expiratory vital capacity (FVC) curves and to measure maximum expiratory flow-volume (MEFV) relationships in intubated infants and children. However, the influence of the endotracheal tube (ETT) on the site of flow limitation, the shape and the analysis of the resultant MEFV curves have not been defined.

Nine anaesthetized (thiopentone, $8 \mathrm{mg} \cdot \mathrm{kg}^{-1} \cdot \mathrm{h}^{-1}$ ) rhesus monkeys (mean weight ( \pm SEM) $10 \pm 1 \mathrm{~kg}$ ) were intubated consecutively with ETTs of different internal diameters (ID 3.0-5.5 $\mathrm{mm}$, at intervals of $0.5 \mathrm{~mm}$ ); the largest representing the appropriate ETT size for the animal. Quadruplicate MEFV curves were generated by FD using the standard $+40 \mathrm{cmH}_{2} \mathrm{O}$ insp/-40 $\mathrm{cmH}_{2} \mathrm{O}$ exp pressures and recorded at each ETT diameter. The effect of the different ETT diameters on the FD flowvolume curve was analysed by comparing maximum expiratory flows at isovolume points at 50, 25 and $10 \%$ FVC (MEF50, MEF25 and MEF10, respectively).

The shape of the resulting MEFV curves could be divided into an initial horizontal part (tube-dependent), and a final descending slope (airway-dependent). No difference in FVC occurred irrespective of the ETT size ( $>>0.05$ by analysis of variance (ANOVA)). MEF50 increased with increasing tube diameter $(p<0.05)$. MEF25 remained unchanged using ETTs which were less than $1.5 \mathrm{~mm}$ smaller than the largest ETT. Smaller ETTs resulted in significantly reduced MEF25 $(p<0.05)$. MEF10 was not influenced by the ETT size.

We conclude that maximum expiratory flows measured by the forced deflation technique are not influenced by an appropriately sized endotracheal tube at lung volumes below $25 \%$ forced vital capacity in our monkey model with normal lungs. We postulate that the effect of endotracheal tubes on maximum expiratory flow volume curves in intubated infants might be of similar or even smaller magnitude, which remains to be established.

Eur Respir J 1997; 10: 1870-1873.

Recent technical developments allow pulmonary function measurements to be performed in even the sickest of infants $[1,2]$. However, it is important to note that, in the case of intubated patients, measurements of pulmonary function include the physical properties of the endotracheal tube (ETT) [3]. Previous studies examining this problem have focused on the measurements of passive respiratory mechanics and found that these measurements are affected by the length and the diameter of the ETT [4-6].

The forced deflation technique (FD) has increasingly been used to measure maximum expiratory flow-volume (MEFV) relationships and forced vital capacity (FVC) in intubated animals and human infants unable to generate a voluntary maximum expiratory manoeuvre $[1$, $3,7,8]$. We have previously demonstrated flow limitation by FD in intubated rhesus monkeys [9, 10] and intubated normal infants [11] at lung volumes below $25 \% \mathrm{FVC}$, using a deflation pressure of $-40 \mathrm{cmH}_{2} \mathrm{O}$ and an appropriately sized ETT. The presence of intrathoracic flow limitation during part of the expiration is likely to abolish the effect of the ETT resistance on flow measurements at low lung volume subdivisions. Knowledge of the influence of the ETT is a necessary prerequisite for standardization and validation of the FD
*Pediatric Intensive Care Unit, Children's Hospital, University of Basel, Switzerland. **Division of Pediatric Critical Care, Children's Hospital of Los Angeles, USC School of Medicine, Los Angeles, CA, USA.

Correspondence: J. Hammer Pediatric Intensive Care Unit Children's Hospital Basel Römergasse 8

4005 Basel

Switzerland

\section{Keywords: Flow limitation}

forced expiration

forced vital capacity

infant pulmonary function testing

maximum expiratory flow-volume curves

\section{Received: October 301996}

Accepted after revision April 131997

Supported by Novartis AG, Basel, Switzerland, which allowed the use of the study animals and the Primate Lung Function Laboratory at no cost. technique, as recently pointed out by an American Thoracic Society/European Respiratory Society (ATS/ERS) Working Group on infant lung function testing [3].

We, therefore, studied the influence of the internal ETT diameter on the shape of the FD flow-volume curves and respective flow and volume measurements in anaesthetized rhesus monkeys, using the standard $+40 \mathrm{cmH}_{2} \mathrm{O}$ insp/-40 $\mathrm{cmH}_{2}$ Oexp pressures. The aim of this study was to characterize the limitations of the FD technique by defining the volume points at which ETTs start to affect maximum expiratory flow measurements.

\section{Methods}

Nine male rhesus monkeys (Macaca mulatta) with a mean age of $8.7 \pm 0.5$ yrs (range $7-11.5 \mathrm{yrs}$ ) and a mean weight of $9.8 \pm 0.6 \mathrm{~kg}$ (range $5.6-11.6 \mathrm{~kg}$ ) were used in these studies. All animals were initially sedated intramuscularly with ketamine $\left(40 \mathrm{mg} \cdot \mathrm{kg}^{-1}\right)$, and anaesthetized intravenously by infusion of thiopentone sodium $\left(8.0 \mathrm{mg} \cdot \mathrm{kg}^{-1} \cdot \mathrm{h}\right)$ for the duration of the experiment. The larynx, epiglottis and vocal cords were anaesthetized with $2 \mathrm{~mL}$ of topical xylocaine (1\% solution). Each animal was intubated consecutively with cuffed ETTs 
(Mallinckrodt, Glens Falls, NY, USA) of different internal diameters (ID) ranging 3.0-5.5 $\mathrm{mm}$ (at intervals of $0.5 \mathrm{~mm}$ ). The ETTs were changed in random order, the largest representing the appropriate size for the monkeys. All ETTs were cut to the same length $(16 \mathrm{~cm})$ and care was taken to ensure they had comparable curvatures. The cuff was inflated during the experiment to prevent any air leak detectable by auscultation when the lungs were inflated to $+60 \mathrm{cmH}_{2} \mathrm{O}$ pressure.

The animals breathed room air spontaneously, and the stomach contents were drained via paediatric nasogastric tube. The animals were placed in the supine/left lateral position, and body temperature was monitored with an oesophageal probe and maintained between 37.8 and $38.2^{\circ} \mathrm{C}$. Three-lead continual electrocardiographic monitoring was performed, and respiratory rate was determined by changes in thoracic electrical impedance (Sirecust Model 1281; Siemens, Erlangen, Germany). Arterial oxygen saturation was monitored by pulse oximetry (Nellcor, Hayward, CA, USA). Each animal was suctioned for secretions at the beginning of testing and, subsequently, as necessary.

FD manoeuvres were performed as described previously [9-11]. Briefly, the lungs were inflated by squeezing a $0.5 \mathrm{~L}$ Jackson-Rees anaesthesia bag, filled from a continuous compressed air supply with an inspired oxygen fraction $\left(F \mathrm{I}, \mathrm{O}_{2}\right)$ of 0.21 . The inflation gas flow was delivered through the side port of a three-way directional sliding valve (Series 8540; Hans Rudolph, Kansas City, MO, USA) placed at the proximal end of the ETT. Inflation pressures of $+40 \mathrm{cmH}_{2} \mathrm{O}$ were generated and held static for at least $3 \mathrm{~s}$, after which the monkey's airways were opened to a $100 \mathrm{~L}$ negative pressure reservoir through a pneumotachograph (Model 4700; Hans Rudolph, Kansas City, MO, USA) linear between 0.01 and $1.7 \mathrm{~L} \cdot \mathrm{s}^{-1}$. An identical airway opening pressure of $-40 \mathrm{cmH}_{2} \mathrm{O}$ was used for all manoeuvres. The lungs were deflated until expiratory flow ceased at residual volume. Quadruplicate manoeuvres were performed and recorded at each tube diameter.

The resultant flow and integrated volume signals were recorded as MEFV curves utilizing a personal computerbased data acquisition system (Model 2600 Pediatric Pulmonary Cart; SensorMedics, Anaheim, CA, USA). Prior to the study volume signals were calibrated using a $100 \mathrm{~mL}$ syringe (Series 5510; Hans Rudolph, Kansas City, MO, USA). Maximum expiratory flows obtained with the different ETTs were compared at isovolume points at 50, 25 and 10\% FVC (MEF50, MEF25 and MEF10, respectively). The exhaled volume obtained from the manoeuvre with the largest ETT served as the reference volume for the calculation and comparison of flow rates at isovolume points, with the curves anchored at residual volume. For each ETT diameter the FD manoeuvre achieving the highest flows was analysed. A one-way analysis of variance (ANOVA) was used for overall group comparisons, with a p-value of less than 0.05 considered significant, the grouping variable being the ETT diameter. Bonferroni adjustment was used to determine differences among groups.

Animals were maintained in an in-house colony at Sandoz AG, Basel, Switzerland, under the full-time care of an experienced primate veterinarian and his staff. Animals were fed and housed under conditions allowing normal growth, play, and social interactions. All experimental protocols conformed to international standards of animal welfare and were approved and periodically reviewed by the Kantonale Tierversuchs-Kommission von Basel-Stadt und Baselland, the independent external body for animal experimentation.

\section{Results}

As displayed in figure 1, the MEFV curve is affected at lower and lower lung volumes with decreasing ETT diameters. The MEFV curves could be divided into an initial, nearly horizontal part (tube-dependent) and a final descending slope (airway-dependent). All curves overlapped in the shared descending portions.

$\mathrm{FVC}$ and flows at the various subdivision of FVC measured at the respective internal ETT diameters are displayed (as mean士SEM) in table 1 . There were no significant differences in FVC, irrespective of the ETT diameter used $(\mathrm{F}=0.129 ; \mathrm{p}=0.98$ by ANOVA). MEF50 was significantly different with the different ETT sizes $(\mathrm{F}=66.75 ; \mathrm{p}<0.0001$ by ANOVA). There was no significant difference in MEF50 between the ETTs of 5.0 and $5.5 \mathrm{~mm}$ ID (Bonferroni $\mathrm{p}>0.05$ ). This is most likely to be due to the greater scatter of the flow data, because individual MEFV curves overlapped in only two of the nine monkeys at 50\% FVC. MEF25 was also significantly different between all groups $(\mathrm{F}=9.33$; $\mathrm{p}<0.0001$ by ANOVA). However, there was no significant difference in MEF25 between the ETTs of 4.5, 5.0 and $5.5 \mathrm{~mm}$ ID (Bonferroni $\mathrm{p}>0.05$ ) in the mean data. MEFV curves overlapped at $25 \%$ FVC with the three largest ETTs (4.5, 5.0 and $5.5 \mathrm{~mm}$ ID) in six of the nine monkeys, and with the two largest ETTs in eight of the nine monkeys. MEF10 were not significantly different between all groups $(\mathrm{F}=0.657 ; \mathrm{p}=0.657$ by ANOVA). Individual MEFV curves overlapped at $10 \% \mathrm{FVC}$ in all monkeys using ETTs $\geq 3.5 \mathrm{~mm}$ ID.

The mean \pm SEM intraindividual coefficients of variation obtained from the four FD manoeuvres at each ETT

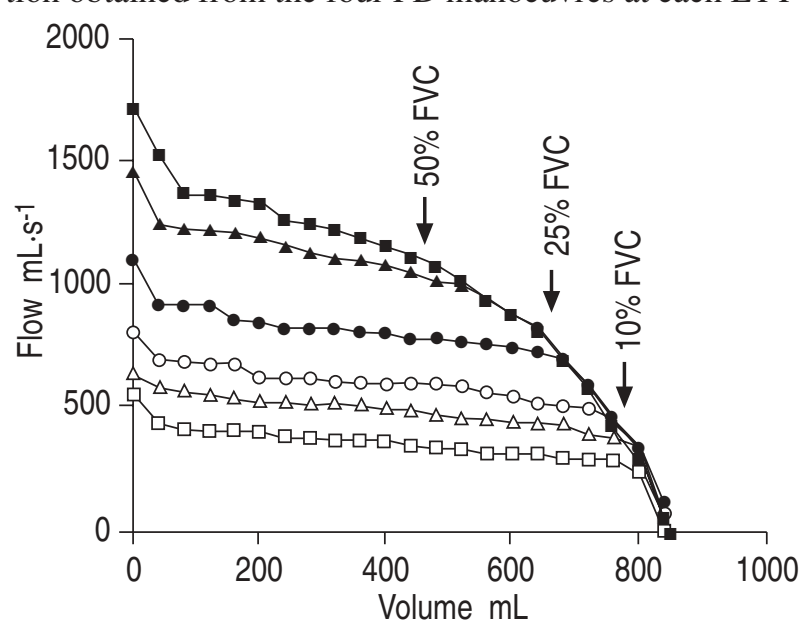

Fig. 1. - Representative forced deflation (FD) flow-volume curves from one rhesus monkey intubated consecutively with cuffed endotracheal tubes (ETT) of different internal diameters (ID). The curves can be visually divided into an initial, nearly horizontal, part and a final descending slope, and demonstrate the influence of the tube diameter on their shape and flow measurements at defined volume subdivisions. ——: ETT $5.5 \mathrm{~mm} \mathrm{ID;} \mathrm{——:} \mathrm{ETT} 5.0 \mathrm{~mm} \mathrm{ID;} \mathrm{——:} \mathrm{ETT}$ $4.5 \mathrm{~mm}$ ID; ——: ETT $4.0 \mathrm{~mm}$ ID: — —: ETT $3.5 \mathrm{~mm} \mathrm{ID;} \mathrm{— \square -}$ : ETT $3.0 \mathrm{~mm}$ ID. 
Table 1. - Maximum expiratory flows and forced vital capacity from forced deflation manoeuvres in nine anaesthetized rhesus monkeys intubated with cuffed endotracheal tubes of different internal diameters

\begin{tabular}{lcccc}
\hline $\begin{array}{l}\text { ETT ID } \\
\mathrm{mm}\end{array}$ & $\begin{array}{c}\text { MEF50 } \\
\mathrm{mL} \cdot \mathrm{s}^{-1}\end{array}$ & $\begin{array}{c}\text { MEF25 } \\
\mathrm{mL} \cdot \mathrm{s}^{-1}\end{array}$ & $\begin{array}{l}\text { MEF10 } \\
\mathrm{mL} \cdot \mathrm{s}^{-1}\end{array}$ & $\begin{array}{c}\mathrm{FVC} \\
\mathrm{mL} \cdot \mathrm{kg}^{-1}\end{array}$ \\
\hline 3.0 & $327 \pm 13^{*}$ & $285 \pm 16^{*}$ & $217 \pm 37^{*}$ & $79.7 \pm 2.9^{*}$ \\
3.5 & $457 \pm 9^{\sharp}$ & $385 \pm 12^{\ddagger}$ & $253 \pm 37^{*}$ & $81.9 \pm 3.5^{*}$ \\
4.0 & $589 \pm 7^{\sharp \#}$ & $491 \pm 32^{\ddagger}$ & $266 \pm 42^{*}$ & $81.5 \pm 3.6^{*}$ \\
4.5 & $730 \pm 24^{\#}$ & $580 \pm 45^{\#}$ & $254 \pm 40^{*}$ & $82.1 \pm 3.5^{*}$ \\
5.0 & $932 \pm 49^{\$}$ & $692 \pm 70^{\$}$ & $198 \pm 24^{*}$ & $83.4 \pm 3.4^{*}$ \\
5.5 & $1040 \pm 65^{\$+}$ & $702 \pm 102^{\$}$ & $205 \pm 23^{*}$ & $83.0 \pm 2.9^{*}$ \\
\hline
\end{tabular}

Values are presented as mean \pm SEM. In each column, values with the same symbol are not significantly different (Bonferroni $\mathrm{p}>0.05$ ). ETT: endotracheal tube; ID: internal diameter; FVC: forced vital capacity; MEF50: maximum expiratory flow at 50\% FVC; MEF25: maximum expiratory flow at 25\% FVC: MEF10: maximum expiratory flow at $10 \%$ FVC.

diameter were $1.4 \pm 0.6 \%$ for $\mathrm{FVC}, 4.7 \pm 0.2 \%$ for $\mathrm{MEF} 25$ and $9.5 \pm 0.5 \%$ for MEF10, which illustrates the good reproducibility of the technique under controlled conditions.

\section{Discussion}

The main finding of this study is that in rhesus monkeys with normal lungs, maximum expiratory flows measured by the FD technique at low lung volumes (MEF25 and MEF10) are not influenced by an appropriately sized ETT and, therefore, represent small airway function. Peak expiratory flows and, usually, MEF50 are influenced by the resistance of the ETT and are, therefore, meaningless. In contrast, the measurement of FVC is not influenced by the ETT size. These findings validate the current analytical practice of FD manoeuvres, and may be helpful in setting standards for performance and interpretation of MEFV curves in intubated infants.

The analysis of MEFV relationships provides a sensitive test of lung function abnormalities, and contributes greatly to the diagnosis and treatment of obstructive lung disease. The occurrence of flow limitation is responsible for the reproducibility of the MEFV curve, which represents the airway conductance upstream of the flow limiting segment of the tracheobronchial tree [12]. The FD technique is the recommended method to generate MEFV manoeuvres in intubated infants, and has previously been used to assess bronchial hyperreactivity and bronchodilator responsiveness in infants with various causes of respiratory failure [13-15]. A recognized limitation of the FD technique is its requirement for the presence of an ETT. As with all other techniques of pulmonary function testing in intubated patients, the physical tube characteristics will affect subsequent results. In particular, the resistance to airflow is influenced by the tube's physical properties, and acts as an elevated resistance to the entire flow entering and leaving the respiratory system.

Techniques measuring dynamic or passive respiratory mechanics are frequently used to assess pulmonary function in intubated infants and to interpret the results in terms of a linear, single-compartment model of the respiratory system [2]. This model, quite apart from its obvious limitation in representing inhomogeneous lung disease, is particularly affected by the influence of the ETT resistance [4-6]. The resistive properties of the
ETT may distort the shape of the passive expiratory flow-volume curve making the calculation of an accurate time constant difficult or impossible $[2,16]$, because of errors related to the extrapolation towards zero flow and zero volume.

In contrast to measurements of respiratory mechanics, forced expiratory manoeuvres are characterized by the generation of intrathoracic flow limitation during all or part of the expiration. We have recently validated the FD technique by demonstrating effort and volume independence of flow measurements below $25 \%$ FVC with an airway opening pressure of $-40 \mathrm{cmH}_{2} \mathrm{O}$ in intubated rhesus monkeys and intubated infants without lung disease [9-11]. Flow limitation occurs at a given lung volume when there is a site in the airways where intrabronchial and intrapleural pressures equalize, acting like a fixed resistance (equal pressure point). As exhalation progresses, the equal pressure point moves deeper into the lung, because airway resistance increases as lung volume falls [17]. It follows that the ETT resistance will be negligible for maximum expiratory flow measurements at volume subdivisions where the airway resistance is higher than the resistance of the ETT.

The MEFV curve generated by the FD technique is affected at lower and lower lung volumes with decreasing ETT diameters and the overall shape of the MEFV curve is typically distorted by the use of small ETTs. If an orifice offers a significant resistance at the end of a breathing system, it initially limits expiratory flow until a lower lung volume is reached, at which point the lung becomes flow limiting. Hence, the shape of the MEFV curve is characterized by an initial horizontal part representing the resistive properties of the ETT, and a final descending slope representing the airway resistance upstream of the respective lung volume points. The sloping plateau of the initial part of the FD curves is probably caused by the decline in elastic recoil pressure and the increase of the respiratory resistance at lower lung volumes. Similar shapes have been described by Olafson and HyatT [18] in adults who forcefully exhaled through orifices of different sizes. It follows that for data acceptance, the shape of the MEFV curve needs to be evaluated critically when analysing maximum expiratory flows generated through an ETT. Such measurements should be ignored if they occur at volume points in the (initial) horizontal part of the MEFV curve. This is also of clinical importance, because children are usually intubated with ETTs smaller than the corresponding tracheal diameter, to avoid pressure in the subglottic region. If cuffed ETTs are considered in paediatric patients, it has been recommended to use a cuffed ETT which is $0.5 \mathrm{~mm}$ ID smaller than the calculated uncuffed ETT for age, to prevent either short-term (postextubation stridor) or long-term (subglottic stenosis) complications [19]. Our study demonstrates that the internal ETT diameter had no influence on MEF25 and MEF10, if appropriately sized ETTs (according to current recommendations) are used.

Nevertheless, data obtained from mature rhesus monkeys may not be applicable to infants due to differences in airway anatomy. Our previous studies applying FD from $+40 \mathrm{cmH}_{2} \mathrm{O}$ in intubated, normal infants demonstrated flows at 25 and $10 \%$ FVC [11], which are about $50 \%$ lower than those obtained in rhesus monkeys [9, 
10]. This would suggest that the rhesus monkeys have larger airways than infants of comparable weight. These considerations make it likely that maximum expiratory flows are unaffected by the ETT diameter at even higher lung volumes in infants and children when compared to rhesus monkeys. It is unlikely that the relative fraction of FVC at which the ETT influences maximum expiratory flows will change significantly with lung growth. The very few published studies in which forced expiratory flows and lung volumes were measured in a large group of infants found that maximum flow at functional residual capacity ( $V^{\prime} \max , \mathrm{FRC}$ ) and FRC increase in proportion, suggesting isotopic growth of airways and lung parenchyma in infants and children [20-22]. This might be different in neonates, who may have higher sizecorrects flows than older children [23]. However, in the presence of obstructive airways disease (e.g. bronchopulmonary dysplasia), where forced expiratory flow analysis will be most useful, the influence of the ETT will be less marked and will affect flows only at even higher lung volumes than in normal lungs.

In conclusion, the present study demonstrated that measurements of maximum expiratory flows below 25\% forced vital capacity by the forced deflation technique represent airway flow and not tube flow in intubated rhesus monkeys, if appropriately sized endotracheal tubes are used. This suggests that maximum expiratory flows below this volume can be used to assess airway function in intubated infants and children, and that flows above this volume should be used with caution, especially in the absence of airways disease. Standardization of performance, interpretation and analysis of techniques are some of the more pressing tasks in infant pulmonary function testing, which are difficult to attain even in the intensive care unit (e.g. varied ventilator settings, endotracheal tube sizes), where study conditions can usually be more tightly controlled. The findings in this study should be relevant to the documentation of normative data and the comparison of forced expiratory manoeuvres, even if the patients are intubated with different size endotracheal tubes.

Acknowledgements: The authors are indebted to B Richardson (Novartis AG, Basel, Switzerland) for the opportunity to use the research facilities. The authors wish to thank their colleague, A. Harnist (Primate Lung Function Laboratory, Novartis, Basel, Switzerland) for excellent technical support.

\section{References}

1. Hammer J, Newth CJL. Infant lung function testing in the intensive care unit. Intensive Care Med 1995; 21: 744-752.

2. Sly PD, Brown KA, Bates JHT, Spier S, Milic-Emili J. Noninvasive determination of respiratory mechanics during mechanical ventilation of neonates: a review of current and future techniques. Pediatr Pulmonol 1988; 4: 39-47.

3. American Thoracic Society/European Respiratory Society. Respiratory mechanics in infants: physiologic evaluation in health and disease. Am Rev Respir Dis 1993; 147: 474-496.

4. Sullivan M, Paliotta J, Saklad M. Endotracheal tube as a factor in measurements of respiratory mechanics. $J$ Appl Physiol 1976; 41: 590-592.
5. Conti G, De Blasi RA, Lappa A, et al. Evaluation of respiratory system resistance in mechanically ventilated patients: the role of the endotracheal tube. Intensive Care Med 1994; 20: 421-424.

6. Wright PE, Marini JJ, Bernard GR. In vitro versus in vivo comparison of endotracheal tube airflow resistances. Am Rev Respir Dis 1989; 140: 10-16.

7. LeSouëf PN, Castile R, Turner DJ, Motoyama E, Morgan WJ. Forced expiratory manoeuvres. In: Stocks J, Sly PD, Tepper RS, Morgan WJ, eds. Infant Respiratory Function Testing. New York, Wiley-Liss, 1996; pp. 379-409.

8. Motoyama EK. Pulmonary mechanics during early postnatal years. Pediatr Res 1977; 11: 220-223.

9. Newth CJL, Amsler B, Anderson GP, Morley J. The effects of varying inflation and deflation pressures on the maximal expiratory deflation flow-volume relationship in anesthetized rhesus monkeys. Am Rev Respir Dis 1991; 144: 807-813.

10. Hammer J, Sivan Y, Deakers TW, Newth CJL. Flow limitation in anesthetized rhesus monkeys: a comparison of rapid thoracoabdominal compression and forced deflation techniques. Pediatr Res 1996; 39: 539-546.

11. Hammer J, Newth CJL. Effort and volume dependence of forced-deflation flow-volume relationships in intubated infants. J Appl Physiol 1996; 80: 345-350.

12. Hyatt RE. Expiratory flow limitation. $J$ Appl Physiol: Respirat Environ Exercise Physiol 1983; 55: 1-8.

13. Koumbourlis AC, Mutich RL, Motoyama EK. Contribution of airway hyperresponsiveness to lower airway obstruction after extracorporeal membrane oxygenation for meconium aspiration syndrome. Crit Care Med 1995; 23: 749-754.

14. Mallory GB, Motoyama EK, Koumbourlis AC, Mutich RL, Nakayama DK. Bronchial reactivity in infants in acute respiratory failure with viral bronchiolitis. Pediatr Pulmonol 1989; 6: 253-259.

15. Hammer J, Numa A, Newth CJL. Albuterol responsiveness in infants with respiratory failure caused by respiratory syncytial virus infection. J Pediatr 1995; 127: 485-490.

16. Brown K, Sly PD, Milic-Emili J, Bates JHT. Evaluation of the flow-volume loop as an intraoperative monitor of respiratory mechanics in infants. Pediatr Pulmonol 1989; 6: 8-13.

17. Mead J, Turner JM, Macklem PT, Little JB. Significance of the relationship between lung recoil and maximum expiratory flow. J Appl Physiol 1967; 22: 95-108.

18. Olafsson S, Hyatt RE. Ventilatory mechanics and expiratory flow limitation during exercise in normal subjects. J Clin Invest 1969; 48: 564-573.

19. Deakers TW, Reynolds G, Stretton M, Newth CJL. Cuffed endotracheal tubes in pediatric intensive care. $J$ Pediatr 1994; 125: 57-62.

20. Hanrahan JP, Tager IB, Castile RG, Segal MR, Weiss ST, Speizer FE. Pulmonary function measures in healthy infants: variability and size correction. Am Rev RespirDis 1990; 141: 1127-1135.

21. Tepper RS, Morgan WJ, Cota K, Wright A, Taussig LM, GHMA Pediatricians. Physiologic growth and development of the lung during the first year of life. Am Rev Respir Dis 1986; 134: 513-519.

22. Tepper RS, Reister T. Forced expiratory flows and lung volumes in normal infants. Pediatr Pulmonol 1993; 15: 357-361.

23. Taussig LM, Landau LI, Godfrey S, Arad I. Determinants of forced expiratoy flows in newborn infants. J Appl Physiol: Respirat Environ Exercise Physiol 1982; 53: 1220-1227. 